\title{
Different effects of insulin and oral antidiabetic agents on glucose and energy metabolism in Type 2 (non-insulin-dependent) diabetes mellitus
}

\author{
L.Groop, E. Widén, A. Franssila-Kallunki, A. Ekstrand, C. Saloranta, C. Schalin and J.Eriksson \\ Fourth Department of Medicine, Helsinki University Hospital, Helsinki, Finland
}

\begin{abstract}
Summary. Which therapy should be used in Type 2 (noninsulin-dependent) diabetic patients with "secondary sulfonylurea failure", insulin or a combination of sulfonylurea and metformin? To address this question, we have compared the effect of 6 months of insulin therapy twice daily with that of a combination of glibenclamide and metformin in 24 Type 2 diabetic subjects, who no longer responded to treatment with sulfonylureas. Both treatments resulted in an equivalent $30 \%$ improvement in mean daily blood glucose $(p<0.001)$, without significant effect on serum lipids. Insulin improved glycaemic control primarily by reducing basal hepatic glucose production $(p<0.05)$, but had no significant effect on peripheral glucose metabolism. The combination of glibenclamide and metformin enhanced significantly total
\end{abstract}

body glucose metabolism $(p<0.05)$, predominantly by stimulating the non-oxidative pathway. Neither insulin nor the combination therapy altered B-cell response to a test meal. Insulin therapy resulted in a $6 \%$ increase in body weight, $63 \%$ of which was accounted for by increased fat mass. Although body weight was unchanged during sulfonylurea/metformin therapy, lean body mass and energy expenditure decreased significantly $(p<0.05)$. We conclude that insulin and glibenclamide/metformin have different long-term effects on glucose and energy metabolism in Type 2 diabetes.

Key words: Type 2 (non-insulin-dependent) diabetes mellitus sulfonylurea, metformin, insulin, secondary drug failure, energy.
Although secondary failure to treatment with sulfonylureas is a common problem in the treatment of Type 2 (non-insulin-dependent) diabetes mellitus [1-3], there is no concensus about how to handle this problem [4-7]. A recent editorial recommended starting insulin before rather than after two years of hyperglycaemic malaisse [5], but this view has been challenged by others $[8,9]$. The extent of the dilemma was obvious in the concensus statement by the European NIDDM Policy Group [7], suggesting that insulin therapy should be started in a patient with Type 2 diabetes "not too soon and not too late". Whereas sulfonylureas and insulin seem to have the same hypoglycaemic properties in patients with newly diagnosed Type 2 diabetes [10,11], the results in patients with secondary sulfonylurea failure are inconsistent $[6,8,12,13]$.

Given these conflicting results we decided to compare the metabolic effects of insulin (intermediary and short-acting insulin twice daily) with that of maximum doses of sulfonylurea and metformin in Type 2 diabetic patients with secondary failure to sulfonylureas. The second aim was to study the mechanisms by which these treatments lowered blood glucose. Thirdly, since insulin treatment has been associated with weight gain [5], we also examined the effect of treatment on energy expenditure and changes in body composition.

\section{Subjects and methods}

Twenty-four patients with Type 2 diabetes (Table 1), who no longer responded to treatment with sulfonylureas, were block-randomized to two different treatment regimes for 6 months; (1) a combination of short and intermediary acting insulin given twice daily (mean \pm SEM of daily insulin dose $=47 \pm 4 \mathrm{IU}$ ) (Insulin); and (2) combination of $21 \mathrm{mg}$ of glibenclamide and $1.5 \mathrm{~g}$ of metformin (O.H.A.) Patients were classified as non-responders to sulfonylurea therapy, if they after an initial good response of at least one year, were in poor glycaemic control (see below) despite maximum doses of sulfonylurea ( $>15 \mathrm{mg}$ day of glibenclamide or glipizide). Poor glycaemic control was defined as a fasting plasma glucose concentration (mean of last 3 measurements with 2 month intervals) $>10 \mathrm{mmol} / \mathrm{l}$. Ten healthy, non-diabetic subjects ( 6 men, 4 women) served as control subjects. Their age was $49 \pm 3$ years, body mass index was $24.2 \pm 0.9 \mathrm{~kg} / \mathrm{m}^{2}$, and their fasting plasma glucose was $4.7 \pm 0.1 \mathrm{mmol} / \mathrm{l}$. A complete medical work-up was carried out to exclude intercurrent illness or cardiac, hepatic, renal or other endocrine disease. All subjects gave their informed consent before participating. The study protocol was approved by the Ethical Committee of the Fourth Department of Medicine, Helsinki University Hospital.

Before randomization, the patients were followed by the Metabolic Outpatient Clinic for 4-6 months, during which time they were all given the same dietary advice (high fiber diet with $45 \%$ carbohydrates, 35\% fat and 20\% protein) and taught home-monitoring of blood glucose using a reflectance meter (Glucometer II, Ames, Elkhart, Ind, USA). All patients were admitted to hospital for commencement of treatment. After discharge, the patients were asked to measure their blood glucose at home two days a week (morning, before lunch, before dinner, evening) and to record the readings. 
Insulin therapy. The patients were given intermediate and short-acting human insulin (Protaphan and Actrapid Human, Novo Industri, Copenhagen, Denmark) twice daily (before breakfast and dinner) with an insulin pen (Novopen, Novo Industri). The insulin dose was titrated to achieve mean home monitored blood glucose below $8.0 \mathrm{mmol} / \mathrm{l}$ without hypoglycaemic side effects.

O. H.A. The patients were given 6 tablets ( $3.5 \mathrm{mg}$ per tablet) of glibenclamide (Euglucon, Orion, Helsinki, Finland) and 3 tablets $(0.5 \mathrm{~g}$ per tablet) of slow-release metformin (Diformin retard, Medica, Helsinki, Finland) three times daily (before breakfast, before lunch, before dinner). If hypoglycaemic symptoms occurred, or the patient recorded blood glucose concentrations below $3.0 \mathrm{mmol} / 1$ on at least two occasions at home, the dose was reduced.

\section{Experimental design}

Follow-up. After discharge from the hospital the patients were seen in the Metabolic Outpatient Clinic at 1 month intervals for 6 months. Body weight was recorded and blood was drawn for determination of $\mathrm{HbA}_{1}$, fructosamine, cholesterol, HDL-cholesterol, and triglycerides at each visit. In addition, the home-monitored blood glucose data were recorded at each visit.

Metabolic studies. The patients participated in each three experiments before and after therapy; (1) a 3-h test meal; and (2) a 2-h euglycaemic, hyperinsulinaemic clamp; and (3) determination of lean body mass (LBM). The metabolic studies started at $07.30 \mathrm{~h}$ after a $12 \mathrm{~h}$ overnight fast. The test meal consisted of $60 \mathrm{~g}$ of whole wheat bread, $60 \mathrm{~g}$ of cheese, $20 \mathrm{~g}$ of marmelade, $200 \mathrm{ml}$ low-fat milk, $125 \mathrm{ml}$ orange juice and $15 \mathrm{ml}$ coffee (about $600 \mathrm{kcal}$ ). Blood samples were drawn for plasma glucose, insulin and C-peptide determinations at 30 min intervals during the test meal. Since plasma glucose had been lowered by treatment, the plasma glucose concentration was raised to pretreatment level by an infusion of glucose for $30 \mathrm{~min}$ before the start of the second test meal. The glucose infusions in the O.H.A. and insulin groups averaged $3.2 \pm 0.8$ and $5.5 \pm 1.2 \mathrm{mg} / \mathrm{kg} \cdot \mathrm{min}$, respectively.

Euglycaemic insulin clamp. Glucose metabolism was measured using the euglycaemic insulin clamp technique [14] whereas substrate oxidation and energy production were estimated by indirect calorimetry [15]. After obtaining 3 basal samples for glucose and insulin, a primed-constant infusion of short-acting human insulin (Actrapid) was administered at a rate of $45 \mathrm{mU} / \mathrm{m}^{2} \cdot \mathrm{min}$ (about $315 \mathrm{pmol} / \mathrm{m}^{2} \cdot \mathrm{min}$ ). The plasma glucose concentration was determined at 5 min intervals and a variable infusion of $20 \%$ glucose was adjusted to maintain the plasma glucose concentration constant for $120 \mathrm{~min}$ in the control subjects. In the diabetic patients, no glucose was infused until plasma glucose had decreased to the desired level. Therefore, the pre-treatment insulin clamp lasted $165 \pm 5 \mathrm{~min}$ in the insulin group and $164 \pm 6 \mathrm{~min}$ in the O.H.A. group. The lenght of the post-treatment clamp matched the length of the pre-treatment clamp.

At unchanged plasma glucose concentration, the amount of glucose required to maintain euglycaemia equals whole-body disposal of glucose, provided that there is no entry of glucose from the liver. Hepatic glucose production was measured by the isotope dilution technique using [ ${ }^{3} \mathrm{H}$-3-jglucose (Amersham inc, Amersham, UK) administered as a primed $(25 \mathrm{uCi})$ constant $(0.25 \mathrm{uCi} / \mathrm{min})$ infusion for $150 \mathrm{~min}$ and continued throughout the experiment. Blood samples for determination of insulin and ${ }^{3} \mathrm{H}-3$-]glucose specific activity were obtained in the basal state and at $15 \mathrm{~min}$ intervals throughout the insulin clamp.

Indirect calorimetry was employed in the basal state and during the last $60 \mathrm{~min}$ of the insulin clamp to estimate net rates of carbohydrate and lipid oxidation [15]. A computerized, open-circuit system was used to measure gas exchange through a transparent 251 PVC plastic canopy (Deltatrac, Datex, Helsinki, Finland) [16]. Flow was measured by the air-dilution method, carbon dioxide concentration by a conventional infra-red detector, whereas oxygen concentration was measured by a fast differential paramagnetic oxygen sensor. The carbon dioxide concentration of room air was automatically remeasured every $30 \mathrm{~min}$ to avoid errors caused by drift in room air carbon dioxide concentration. The oxygen sensor maintains its ac- curacy for up to $8 \mathrm{~h}$ without recalibration. The monitor has a precision of $2.6 \%$ for oxygen consumption and $1.0 \%$ for carbon dioxide production. Protein oxidation was calculated from the urinary urea nitrogen excretion obtained before and during the insulin clamp.

Lean body mass was determined with the tritiated water dilution technique [17]. Briefly, $40 \mu \mathrm{Ci}$ of tritiated water (Amersham Inc, Amersham, UK) diluted in $\mathrm{NaCl} 0.9 \%$ was given as an iv injection. Blood samples for determination of tritiated water specific activity in plasma were drawn before and 80,100 and 120 min after the injection.

Analytical determinations. The plasma glucose concentration was measured by the glucose oxidase method on a Beckman glucose analyser II (Beckman Instruments, Fullerton, Calif, USA). Glycohaemoglobin concentration in blood was measured by microcolumn chromatography (Isolab, Akron, Ohio, USA). The reference level for the assay was $5-7 \%$. The concentration of serum fructosamine was measured using a commercial kit (Roche Diagnostics, Basel, Switzerland). The reference range for healthy subjects was $2.0-2.7 \mathrm{mmol} / 1$. Serum insulin was measured by a double-antibody radioimmunoassay (Pharmacia, Uppsala, Sweden). C-peptide was measured by radioimmunoassay using a specific guinea pig antiserum raised against human C-peptide (Cambridge Medical Diagnostics, Billerica, Mass, USA). Plasma non-esterified fatty acids (NEFA) were measured with the microfluorometric method described by Miles et al. [18]. $\left.{ }^{3} \mathrm{H}-3\right]-$ glucose specific activity was measured in duplicate on supernatants of $1 \mathrm{~N}$ perchloric acid extracts of plasma samples, after evaporation of radiolabelled water.

\section{Calculations}

Basal hepatic glucose production was calculated by dividing the $\left[{ }^{3} \mathrm{H}-3-\right]$ glucose infusion rate by the steady state plateau of $\left[{ }^{3} \mathrm{H}-3\right.$ - $]$ glucose specific activity achieved during the last $30 \mathrm{~min}$ of the basal tracer infusion period. After administration of insulin and glucose a non-steady state condition in glucose specific activity exists, and the rate of glucose appearance was calculated by a two compartment model [19]. This model is known to produce negative estimates of hepatic glucose production in the presence of high levels of insulin. Negative rates of endogenous (hepatic) glucose production were only rarely observed during the second $h$ of the insulin clamp. These values were taken to indicate that hepatic glucose production was completely suppressed. The infusion rate of cold glucose was integrated over $20 \mathrm{~min}$ intervals and subtracted from the total rate of glucose appearance to obtain the hepatic glucose production rate. Total body glucose metabolism was calculated by adding the mean rate of hepatic glucose production (if a positive number) during the last $60 \mathrm{~min}$ of each insulin clamp step to the mean glucose infusion rate during the same period. Non-oxidative glucose metabolism was calculated as the difference between total body glucose uptake and glucose oxidation, as determined by indirect calorimetry.

Substrate oxidation. Net glucose and lipid oxidation rates were calculated from indirect calorimetric measurements in the basal state and during the last $60 \mathrm{~min}$ of each insulin clamp. The constants to calculate glucose, lipid and protein oxidation from gas exchange data have been described previously [15]. At a non-protein respiratory quotient $>1.0$, the equation for the calculation of substrate oxidation remains valid; the remaining negative value for lipid oxidation is, in fact, equivalent to net fat synthesis [15].

Lean body mass. Total body water was calculated from steady state kinetic data assuming that $1 \mathrm{ml}$ of plasma contains $93 \%$ water. Lean body mass was obtained by dividing total body water by 0.73 , since the lean body mass contains approximately $73 \%$ water. Fat mass was calculated as the difference between body weight and lean body mass.

\section{Statistical analysis}

All data are expressed as mean $\pm S E M$. Differences from baseline were tested by analysis of variance for repeated measurments using a BMDP (Biomedical Data Processing Program, Los Angeles, Calif, USA) computer programme. Differences between group means were 
L.Groop et al.: Insulin or oral antidiabetic agents in Type 2 diabetes?

tested with one-way analysis of variance. Scheffe's test was applied to correct for multiple comparisons. Correlations were tested by linear regression analysis. Area under the C-peptide curves was calculated by the trapezoidal rule.

\section{Results}

\section{Glycaemic control}

Before randomization, the patients were followed by the Outpatient Clinic for 4-6 months. In the insulin group, fasting plasma glucose (from $14.3 \pm 0.8$ to $14.9 \pm 0.7 \mathrm{mmol} / \mathrm{l}$ ) and $\mathrm{HbA}_{1}$ (from $11.0 \pm 0.4$ to $10.4 \pm 0.3 \%)$ did not significantly change, while there was a slight fall in fructosamine concentration (from $4.3 \pm 0.2$ to $3.8 \pm 0.2 \mathrm{mmol} / 1 ; p<0.05)$ during this period. No significant changes were observed during the same period in fasting plasma glucose (from 12.4 \pm 0.6 to $13.4 \pm 0.6 \mathrm{mmol} / \mathrm{l}$ ), $\quad \mathrm{HbA}_{1}$ (from $10.1 \pm 0.4$ to $9.9 \pm 0.3 \%)$ and fructosamine $(3.8 \pm 0.1$ to $3.7 \pm 0.2$ $\mathrm{mmol} / \mathrm{l})$, concentrations in the O.H.A. group.

There was a significant improvement in all parameters of glycaemic control (home monitored blood glucose, $\mathrm{HbA}_{1}$ and fructosamine) within 4 weeks after intensified therapy was started in both groups $(p<0.01)$ (Fig.1). Thereafter, the mean blood glucose concentration measured at home remained unchanged in the insulin and O.H.A. groups throughout the follow-up period. There was no significant difference in blood glucose, $\mathrm{HbA}_{1}$ or fructosamine concentrations between the insulin and O.H.A. groups at any time.

\section{Lipids}

There was no significant change in serum cholesterol concentrations during insulin (from 7.28 \pm 0.55 to $6.73 \pm 0.59 \mathrm{mmol} / \mathrm{l})$ or O.H.A. $(6.42 \pm 0.35$ vs $6.14 \pm 0.33 \mathrm{mmol} / 1)$. HDL-cholesterol concentrations remained virtually unchanged in the insulin $(1.27 \pm 0.12$ vs $1.31 \pm 0.12 \mathrm{mmol} / \mathrm{l})$ and O.H.A. $(1.10 \pm 0.10$ vs $1.17 \pm 0.11 \mathrm{mmol} / \mathrm{l})$ groups. As a consequence, the serum triglyceride concentration did not change significantly during treatment with insulin $(2.35 \pm 0.27$ vs $2.53 \pm 0.83 \mathrm{mmol} / \mathrm{l})$ or O.H.A. $(2.44 \pm 0.33$ vs $2.19 \pm$ $0.27 \mathrm{mmol} / 1)$.

\section{$B$-cell function}

Basal insulin concentration did not significantly change in the insulin (from $10.2 \pm 1.2$ to $12.3 \pm 2.0 \mu \mathrm{U} / \mathrm{ml}$ ) or O.H.A. (15.8 \pm 3.8 vs $10.0 \pm 1.3 \mu \mathrm{U} / \mathrm{ml})$ groups during the treatment period (Fig.2). Neither was there any change in basal C-peptide concentration in the insulin$(0.48 \pm 0.06$ vs $0.47 \pm 0.04 \mathrm{nmol} / 1)$ or O.H.A.-treated $(0.59 \pm 0.07$ vs $0.63 \pm 0.07 \mathrm{nmol} / 1)$ group.

In order to achieve identical experimental conditions during the first and second test meal, the plasma glucose concentration was raised by a variable infusion of glucose before the second test meal. The basal plas-
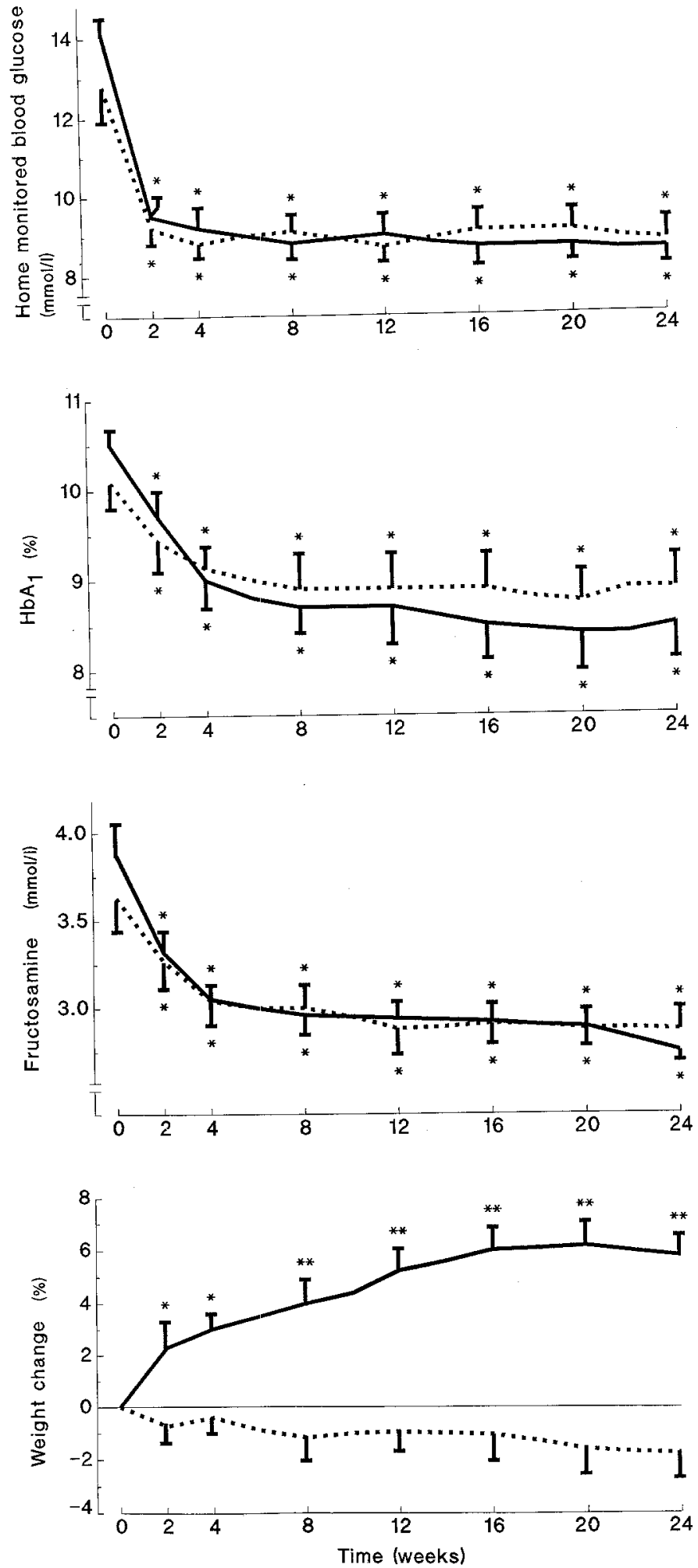

Fig. 1. Change in home monitored blood glucose (mean of 4 measurements per day during two days a week) (top panel), glycohaemoglobin (second panel), serum fructosamine (third panel) concentrations and change in body weight (bottom panel) in patients treated with insulin (unbroken line), or glibenclamide/metformin (dotted line). Values are mean \pm SEM. * $\mathrm{p}<0.01$, significance of difference from baseline

ma glucose concentration during the first and second test meals was $13.2 \pm 0.6$ vs $12.7 \pm 0.7 \mathrm{mmol} / 1$ in the insulin group and $11.9 \pm 0.5$ vs $11.7 \pm 0.8 \mathrm{mmol} / 1$ in the O.H.A. group (Fig. 2). The area under the concentra- 

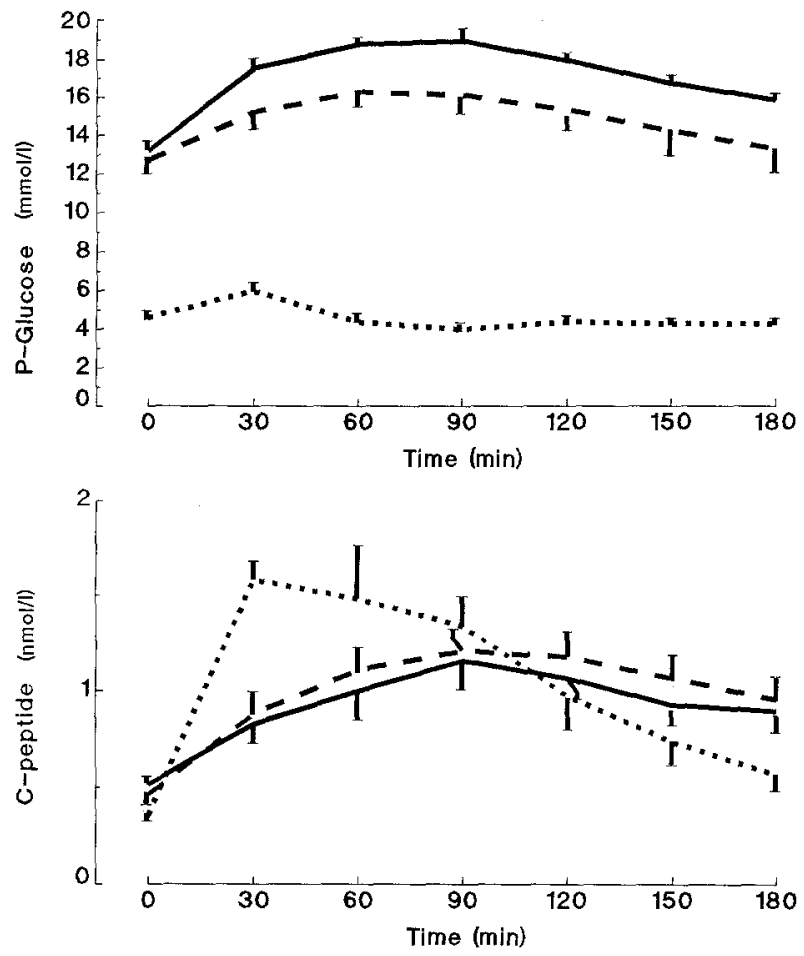

Fig. 2. Plasma glucose (top panel) and C-peptide (bottom panel) responses to test meal before (unbroken line) and after treatment (broken line) with insulin alone (to the left) or a combination of glibenclamide and metformin (to the right). The dotted lines represent data from healthy control subjects. Values are mean \pm SEM

tion curve was similar before and after treatment in the insulin $(5.42 \pm 0.65$ vs $6.16 \pm 0.70 \mathrm{nmol} / 1 \times 180 \mathrm{~min}$; $p=\mathrm{NS})$ and O.H.A. $(6.64 \pm 0.77 \pm 7.03 \pm 0.69 \mathrm{nmol} / 1 \times$ $180 \mathrm{~min} ; p=\mathrm{NS})$ groups.

\section{Glucose metabolism}

Hepatic glucose production. At the beginning of the study, the basal rate of hepatic glucose production (HGP) was enhanced in both the insulin $(4.58 \pm 0.29 \mathrm{mg} / \mathrm{kg} \mathrm{LBM} \cdot \mathrm{min})$ and O.H.A. group $(4.40 \pm 0.36 \mathrm{mg} / \mathrm{kg} \mathrm{LBM} \cdot \mathrm{min})$ compared with healthy control subjects $(2.62 \pm 0.1 \mathrm{mg} / \mathrm{kg} \mathrm{LBM} \cdot \mathrm{min}$; both $p<0.001)$. The enhanced basal rate of HGP was significantly reduced with insulin (to $3.72 \pm 0.30 \mathrm{mg} / \mathrm{kg}$ $\mathrm{LBM} \cdot \min ; \quad p<0.05)$, and less so with sulfonylurea/metformin (to $3.90 \pm 0.19 \mathrm{mg} / \mathrm{kg} \quad \mathrm{LBM} \cdot \mathrm{min}$ ) (Fig. 3). However, even after treatment, basal HGP remained $40-50 \%$ higher in the diabetic patients than in healthy control subjects. During the insulin clamp, hepatic glucose production was completely suppressed in control subjects. Suppression of HGP by insulin was not significantly influenced by insulin or O.H.A. therapy (Fig. 3).

Total glucose metabolism. In the basal state total glucose metabolism equalled the rate of appearance of glucose, i.e. HGP, and was calculated from the isotopic data
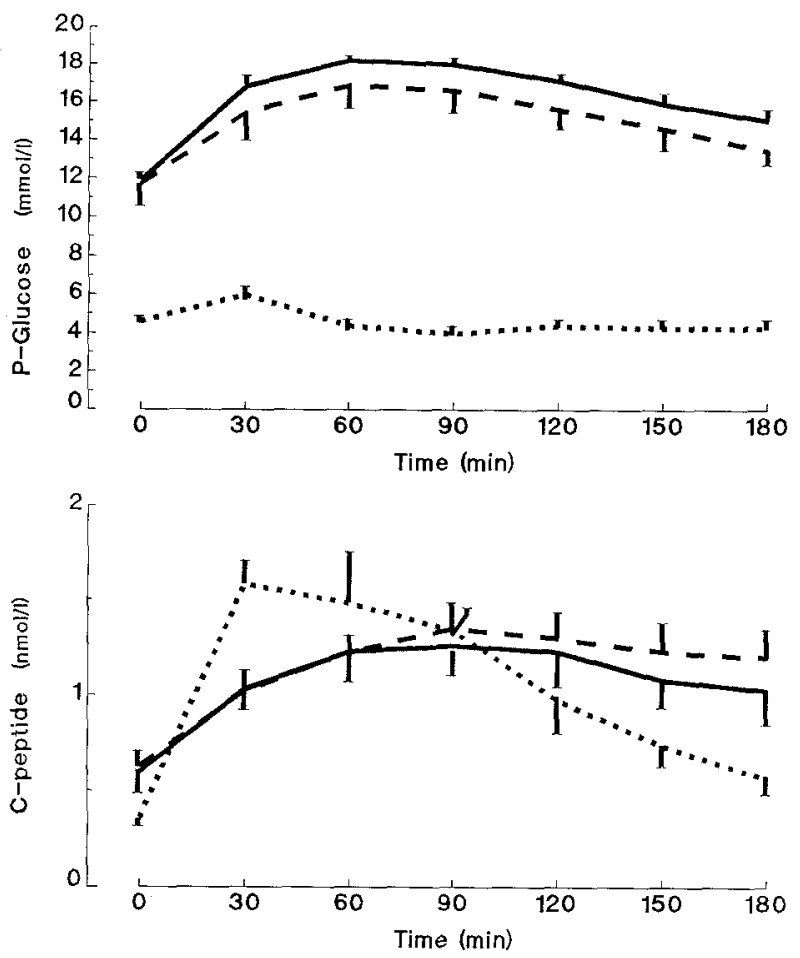

minus glucose loss in the urine. Insulin-stimulated glucose disposal increased by $32 \%$ in the O.H.A. group $(5.07 \pm 0.31$ vs $6.68 \pm 0.82 \mathrm{mg} / \mathrm{kg} \mathrm{LBM} \cdot \mathrm{min} ; p<0.05)$ (Fig. 3). Despite this improvement, total glucose metabolism was still reduced by $21 \%$ in the O.H.A. group compared with the age-matched control subjects $(p<0.05)$. There was no significant increase in total glucose disposal during insulin therapy (from $5.09 \pm 0.25$ to $5.59 \pm 0.55 \mathrm{mg} / \mathrm{kg} \mathrm{LBM} \cdot \mathrm{min})$.

Glucose oxidation. The basal rate of glucose oxidation did not significantly change during insulin (from $1.64 \pm 0.18$ to $1.82 \pm 0.23 \mathrm{mg} / \mathrm{kg} \mathrm{LBM} \cdot \min$ ) or O.H.A. $(1.59 \pm 0.23$ vs $1.84 \pm 0.25 \mathrm{mg} / \mathrm{kg} \mathrm{LBM} \cdot \mathrm{min})$ treatment

Table 1. Clinical characteristics of subjects treated with insulin, a combination of sulfonylurea and metformin (OHA) and in healthy control subjects

\begin{tabular}{lcccc}
\hline & Insulin & O.H.A. & $\begin{array}{l}\text { Control } \\
\text { subjects }\end{array}$ \\
\hline$N$ (females/males) & $12(6 / 6)$ & $12(6 / 6)$ & $10(56 / 56)$ \\
Age (years) & $59 \pm 2$ & $60 \pm 2$ & $49 \pm 3$ \\
Duration (years) & $11 \pm 1$ & $12 \pm 2$ & \\
Body weight $(\mathrm{kg})$ & $76.4 \pm 3.3$ & $77.7 \pm 3.6$ & $72.6 \pm 3.7$ \\
Body mass index $\left(\mathrm{kg} / \mathrm{m}^{2}\right)$ & $27.7 \pm 0.9$ & $26.5 \pm 1.0$ & $24.2 \pm 0.9$ \\
Fat mass $(\%)$ & $38.5 \pm 2.2$ & $35.4 \pm 2.0$ & $29.4 \pm 2.3$ \\
Fasting plasma & & & \\
glucose (mmol/1) & $14.3 \pm 0.7$ & $12.5 \pm 0.4$ & $4.7 \pm 0.1$ \\
Glycohaemoglobin $(\%)$ & $10.7 \pm 0.2$ & $10.4 \pm 0.4$ & $5.9 \pm 0.3$ \\
Fasting insulin $(\mu \mathrm{U} / \mathrm{ml})$ & $10.2 \pm 1.2$ & $15.8 \pm 3.8$ & $6.0 \pm 0.5$ \\
Cholesterol (mmol/1) & $7.3 \pm 0.5$ & $6.4 \pm 0.4$ & $5.8 \pm 0.3$ \\
HDL-Cholesterol $(\mathrm{mmol} / \mathrm{l})$ & $1.3 \pm 0.1$ & $1.1 \pm 0.1$ & $1.5 \pm 0.1$ \\
Triglycerides (mmol/1) & $2.35 \pm 0.27$ & $2.44 \pm 0.33$ & $1.0 \pm 0.5$ \\
\hline
\end{tabular}

Values are mean \pm SEM 
(Fig. 3). During the insulin clamp, there was a 2-fold increase in the rate of glucose oxidation compared with baseline. However, insulin-stimulated glucose oxidation was not significantly altered by insulin $(3.30 \pm 0.27$ vs $3.62 \pm 0.33 \mathrm{mg} / \mathrm{kg} \mathrm{LBM} \cdot \mathrm{min}$ ) or by sulfonylurea/metformin $(3.05 \pm 0.17$ vs $3.33 \pm 0.31 \mathrm{mg} / \mathrm{kg}$ $\mathrm{LBM} \cdot \min )$ therapy.

Non-oxidative glucose metabolism. The basal rate of non-oxidative glucose disposal was enhanced most likely as a consequence of the mass action effect of higher plasma glucose concentrations. Lowering of the fasting plasma glucose concentration by insulin and O.H.A. resulted in a reduced basal rate of non-oxidative glucose disposal (Fig.3). Insulin-stimulated nonoxidative glucose disposal accounted for $35 \%$ of total body glucose disposal in the diabetic patients compared with $50 \%$ in healthy control subjects $(p<0.05)$. Insulin therapy did not significantly alter the rate of non-oxidative glucose disposal. On the other hand, treatment with sulfonylurea/metformin caused a $75 \%$ improvement in non-oxidative glucose metabolism (from $1.98 \pm 0.30$ to $3.46 \pm 0.72 \mathrm{mg} / \mathrm{kg} \mathrm{LBM} \cdot \min ; p=0.07$ ), which was no longer significantly different from the value observed in healthy control subjects $(4.41 \pm 0.19 \mathrm{mg} / \mathrm{kg} \mathrm{LBM} \cdot \mathrm{min})$. There was a large variation in the individual responses to treatment ( 7 increased, 2 unchanged, 2 decreased), which explains the failure to observe a statistically significant difference (at $p<0.05$ level) during treatment.

NEFA and net lipid oxidation. Basal NEFA concentrations were similar before and after treatment with insulin or O.H.A. (Table 2). NEFA concentrations were markedly suppressed during the insulin clamp in both control subjects and diabetic patients, and this suppression was further enhanced in diabetic patients with sulfonylurea/metformin treatment ( $p<0.01$ vs before O.H.A. treatment).

The basal rate of net lipid oxidation was significantly reduced by sulfonylurea/metformin treatment (from $1.53 \pm 0.09$ to $1.31 \pm 0.07 \mathrm{mg} / \mathrm{kg} \mathrm{LBM} \cdot \mathrm{min} ; p<0.02)$ but not with insulin $(1.64 \pm 0.09$ vs $1.49 \pm 0.16 \mathrm{mg} / \mathrm{kg}$ $\mathrm{LBM} \cdot \min ; p=\mathrm{NS}$ ). During the insulin clamp, lipid oxidation was reduced by $70 \%$ in control subjects (from $1.30 \pm 0.11$ to $0.48 \pm 0.11 \mathrm{mg} / \mathrm{kg} \cdot \mathrm{LBM} \cdot \mathrm{min} ; p<0.001$ ). Suppression of lipid oxidation by insulin was not significantly altered by O.H.A. $(0.91 \pm 0.08$ vs $0.79 \pm 0.10 \mathrm{mg} / \mathrm{kg} \mathrm{LBM} \cdot \mathrm{min})$ or insulin $1.0 \pm 0.08$ $\pm 0.84 \pm 0.15 \mathrm{mg} / \mathrm{kg} \mathrm{LBM} \cdot \mathrm{min})$ therapy.

Protein oxidation. The rate of protein oxidation was unaltered by insulin $(0.98 \pm 0.07$ vs $1.07 \pm 0.10 \mathrm{mg} / \mathrm{kg}$ $\mathrm{LBM} \cdot \mathrm{min})$ and sulfonylurea/metformin $(1.05 \pm 0.18 \mathrm{vs}$ $1.11 \pm 0.17 \mathrm{mg} / \mathrm{kg} \mathrm{LBM} \cdot \mathrm{min})$ therapy, and did not significantly differ from the value observed in control subjects $1.07 \pm 0.12 \mathrm{mg} / \mathrm{kg} \cdot \mathrm{LBM} \cdot \mathrm{min}$.

Body composition and energy expenditure. The insulin treated patients gained on average $6 \%(5 \mathrm{~kg})$ in weight over a 4-month period, after which the weight appeared to reach a new steady state (from 76.4 3.3 to

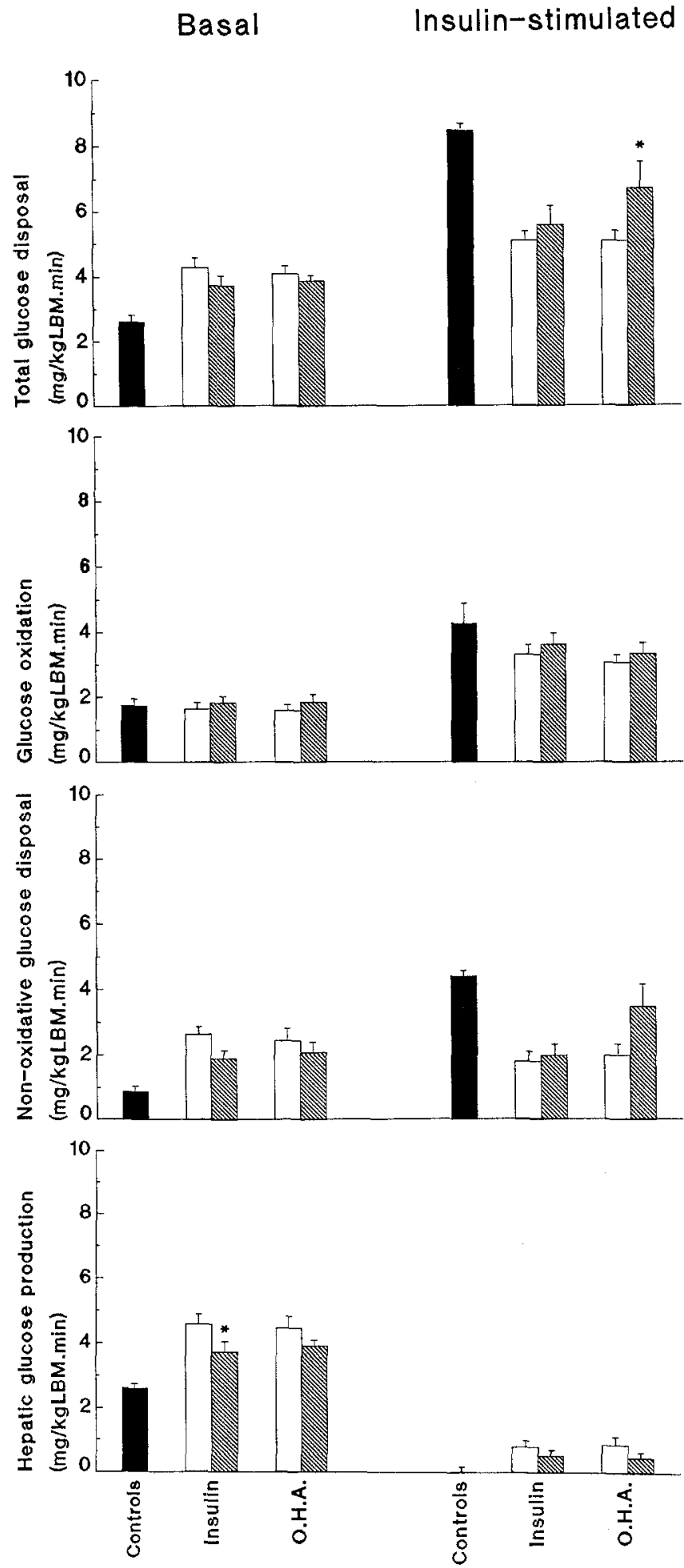

Fig.3. Insulin-stimulated total glucose metabolism (top panel), glucose oxidation (second panel), non-oxidative glucose metabolism (third panel) and hepatic glucose production (bottom panel) in the basal and insulin-stimulated state before (open bars to the left) and after (shaded bars to the right) treatment with insulin alone or a combination of glibenclamide and metformin. Black bars represent data from healthy control subjects. Values are mean \pm SEM

$80.5 \pm 3.7 \mathrm{~kg} ; p<0.001$ ) (Fig. 1). Similarly, BMI rose from $27.3 \pm 1.0$ to $28.8 \pm 1.1 \mathrm{~kg} / \mathrm{m}^{2}(p<0.01)$. There was no change in body weight or BMI in patients treated with sulfonylurea/metformin ( $77.7 \pm 3.6$ to $76.4 \pm 3.9 \mathrm{~kg}$ 
Table 2. Metabolic characteristics of the euglycaemic insulin clamp before and after treatment with insulin twice daily (Insulin) or a combination of maximum doses of glibenclamide and metformin (O.H.A.)

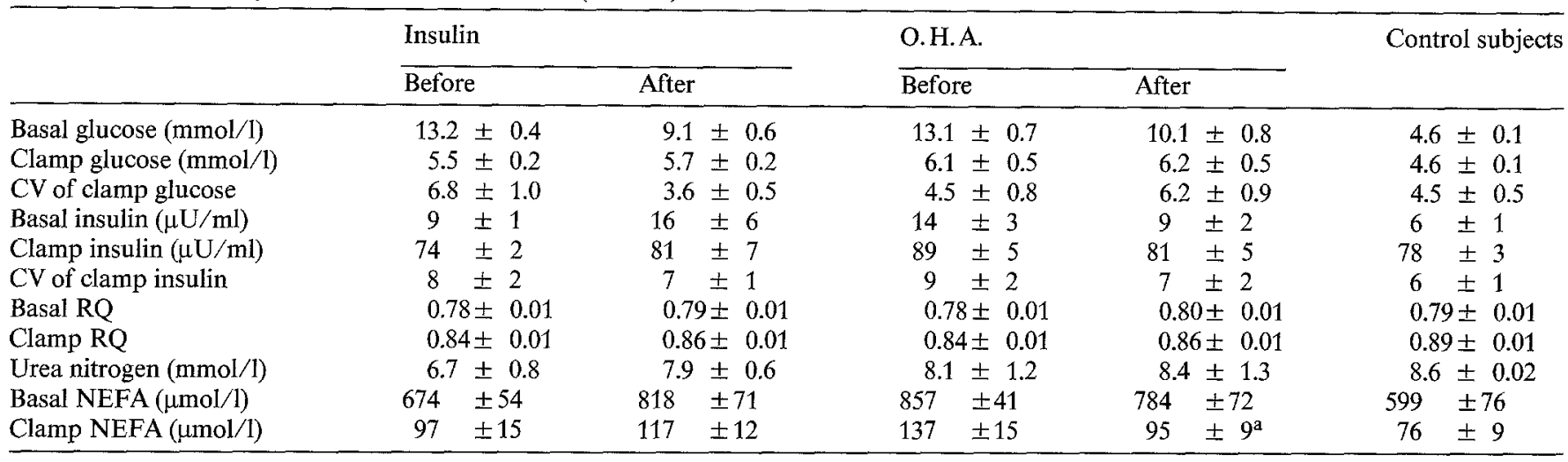

Values are mean \pm SEM. ${ }^{\mathrm{a}} p<0.01$ vs pre-treatment value. $\mathrm{CV}=$ coefficient of variation; $\mathrm{NEFA}=$ non-esterified fatty acid; $\mathrm{RQ}=$ respiratory quotient

and $26.3 \pm 1.1$ to $25.8 \pm 1.1 \mathrm{~kg} / \mathrm{m}^{2}$ ). Increase in fat mass contributed more than the increase in LBM $(63 \%$ vs $37 \%$ ) to the increased body weight in insulin treated patients. In the O.H.A. treated patients, LBM decreased significantly from $50.9 \pm 2.4$ to $48.2 \pm 2.5 \mathrm{~kg}(p<0.05)$. This, in turn, was associated with an increased percentage of fat mass from $35.4 \pm 1.9$ to $37.3 \pm 1.8 \%(p<0.05)$.

Basal and insulin-stimulated energy expenditure did not change during insulin therapy $(1.22 \pm 0.05$ vs $1.21 \pm 0.06 \mathrm{kcal} / \mathrm{min}$ and $1.22 \pm 0.06$ vs $1.23 \pm 0.07$ $\mathrm{kcal} / \mathrm{min}$ ). In contrast, during treatment with sulfonylurea/metformin basal energy expenditure decreased significantly from $1.14 \pm 0.05$ to $1.07 \pm 0.05 \mathrm{kcal} / \mathrm{min}$ $(p<0.05)$. Sulfonylurea/metformin therapy did not significantly alter insulin-stimulated energy expenditure $(1.12 \pm 0.06$ vs $1.08 \pm 0.05 \mathrm{kcal} / \mathrm{min})$. Energy expenditure correlated with lean body mass in all subjects $(r=0.71 ; p<0.001)$.

\section{Discussion}

Treatment with insulin or a combination of glibenclamide and metformin for 6 months resulted in an equivalent $30 \%$ improvement in mean blood glucose concentrations in Type 2 diabetic patients, who had failed to respond to treatment with sulfonylurea alone. In insulin-treated patients, this improvement in glycaemic control was associated with a $6 \%$ increase in body weight, mainly fat mass. Although body weight remained unchanged in the O.H.A. treated patients, their LBM (i.e. muscle mass) decreased significantly during the follow-up period.

The data provide some new insights into the mechanisms by which insulin and sulfonylurea/metformin improve glycaemic control in patients with secondary failure to sulfonylureas. The effect of insulin therapy was primarily explained by enhanced suppression of basal HGP by insulin, while insulin had no significant effect on peripheral glucose uptake. At first glance, these data seem to disagree with a number of previous studies, which reported an average improvement in total body glucose disposal of $47 \%[13,19-24]$ after short-term intensified insulin therapy in Type 2 diabetic patients. There are, however, several differences between the present and previous study designs. In previous reports, the patients were re-studied after an average period of 3 weeks, compared with 6 months in the present study. During such a short period of insulin therapy, there is usually no significant weight gain. In contrast, the insulin-treated patients in the current study gained on average $5 \mathrm{~kg}$ in weight. It is well described that insulin therapy in Type 2 diabetic patients results in weight gain $[5,11]$, but it has not been known to what extent this weight gain is due to an increase in muscle or fat mass. Our data demonstrate that $2 / 3$ of the increase in weight is due to increased fat mass. It is possible, that the metabolic consequences of an increased fat mass have counteracted the possible favourable effect of insulin on peripheral glucose metabolism. There is at least indirect evidence to support this view. In contrast to the O.H.A. group, in which lipid oxidation was reduced by treatment, lipid oxidation remained enhanced during insulin therapy. In addition, suppression of plasma NEFA concentration during the insulin clamp was enhanced by sulfonylurea/metformin treatment. One could therefore postulate the following hypothetical sequence of events; increased fat mass, increased supply of non-esterified fatty acids (NEFA), increased lipid oxidation and through the activation of the Randle cycle, decreased glucose utilization [25].

In contrast to insulin, the addition of metformin to glibenclamide, resulted in enhanced peripheral glucose disposal, mainly enhanced non-oxidative glucose disposal. It has previously been shown, that 3 months of treatment with insulin or tolazamide resulted in a similar improvement in insulin action [10]. The difference between insulin and the combination therapy, must therefore be attributed to the presence of metformin.

In vitro and in vivo studies have shown, that metformin can enhance peripheral glucose uptake [26], especially the oxidation of glucose [27] and decrease gluconeogenesis [28]. In addition, metformin can alter the intestinal absorption of glucose [29]. Interestingly, 
biguanides have also been shown to inhibit NEFA oxidation in rat diaphragm [30]. In the present study, the basal rate of net lipid oxidation was significantly reduced during sulfonylurea/metformin therapy, and this, in turn, was associated with a significant reduction in the basal energy production. Oxidation of lipids produces more energy than oxidation of glucose [15], and reduced lipid oxidation should therefore result in reduced energy expenditure. Furthermore, lean body mass (i.e. muscle mass) decreased during treatment with sulfonylurea/metformin and the decrease in LBM was associated with a decrease in energy expenditure, $(r=0.71 ; p<0.01)$. It is evident, that the patients were in a negative energy balance during treatment with sulfonylurea/metformin. The reasons are unknown, but there are several possibilities. First, it could reflect the natural course of the diabetic disease. Second, it could be a consequence of the inhibitory effect of metformin on intestinal glucose absorption [28]. Third, it could reflect a general inhibition of oxidative processes as suggested for phenformin [30].

In summary, the data suggest, that long-term insulin and glibenclamide/metformin therapy result in an equivalent improvement in glycaemic control by different mechanisms.

But there was also a reverse side to this coin, while insulin resulted in positive, sulfonylurea/metformin resulted in negative energy balance with a decrease in muscle mass.

\section{References}

1. Groop L, Pelkonen R (1984) Treatment failures: A common problem in the management of patients with type 2 diabetes. Acta Endocrinol 105 [Suppl 262]: 131-135

2. Groop LC, Pelkonen R, Koskimies S, Bottazzo GF, Doniach D (1986) Secondary failure to treatment with oral antidiabetic agents in non-insulin dependent diabetes. Diabetes Care 9:129-133

3. Haupt E, Laube F, Loy H, Schöffling K (1977) Secondary failures in modern therapy of diabetes mellitus with blood glucose lowering sulfonamides. Med Klin 72: 1529-1536

4. Tattersall RB, Scott AR (1987) When to use insulin in the maturity onset diabetic? Postgrad Med J 63: 859-864

5. Taylor R (1988) Insulin for the non-insulin dependent? (Editorial) Br Med J 296: 1015-1016J

6. Peacock I, Tattersall RB (1984) The difficult choice of treatment for poorly controlled maturity onset diabetes: tablets or insulin? Br Med J 288: 1956-1959

7. Alberti KGMM, Gries A and the European NIDDM Policy Group (1988) Management of non-insulin dependent diabetes mellitus in Europe: a concensus view. Diab Med 5: 275-281

8. Scott AR, Attenborough Y, Peacock I, Fletcher E, Jeffcoate WJ, Tattersall RB (1988) Comparison of high fibre diets, basal insulin supplements, and flexible insulin treatment for non-insulin dependent (type II) diabetics poorly controlled with sulfonylureas. Br Med J 297: 707-710

9. MacPherson JN (1988) Insulin for the non-insulin dependent? (letter) Br Med J 296: 1401

10. Firth RG, Bell PM, Rizza RA (1986) Effects of tolazamide and exogenous insulin on insulin action in patients with non-insulin dependent diabetes mellitus. N Engl J Med 314: 1280-1286

11. Turner RC and the UK Prospective Study Group. UK Prospective diabetes study. II. Reduction in $\mathrm{HbA}_{1 \mathrm{c}}$ with basal insulin supple- ment, sulfonylurea, or biguanide therapy in maturity-onset diabetes. A multicenter study. Diabetes 34: 793-798

12. Holman RR, Steemson J, Turner RC (1987) Sulphonylurea failure in type 2 diabetes: treatment with basal insulin supplement. Diab Med 4: 457-462

13. Yki-Järvinen H, Nikkilä E, Helve E, Taskinen M-R (1988) Clinical benefits and mechanisms of a sustained response to intermittent insulin therapy in type 2 diabetic patients with secondary drug failure. Am J Med 84: 185-192

14. DeFronzo RA, Tobin JD, Andres R (1979) Glucose clamp technique: a method for quantifying insulin secretion and resistance. Am J Physiol 237: E214-E223

15. Ferrannini E (1988) The theoretical basis for indirect calorimetry: a review. Metabolism 37: 287-301

16. Meriläinen PT (1987) Metabolic monitor. Int J Clin Monitor Comput 4: 167-177

17. Coleman TG, Manning RD Jr, Norman RA Jr, Guyton AC (1972) Dynamics of water-isotope distribution. Am J Physiol 223: 1371-1375

18. Miles JR, Glasscock J, Aikens J, Gerich J, Haymond M (1983) A microfluorometric method for the determination of free fatty acids in plasma. J Lipid Res 24: 96-99

19. Cobelli C, Mari A, Ferrannini E (1987) Non-steady state: error analysis of Steele's model and development for glucose kinetics. Am J Physiol 252: E679-E689

20. Andrews WJ, Vasques B, Nagulesparan M, Klimes I, Foley J, Unger R, Reaven GM (1984) Insulin therapy in obese. Non-insulin dependent diabetes induces improvement in insulin action and secretion that are maintained for two weeks after insulin withdrawal. Diabetes 33: 634-642

21. Ginsberg H, Rayfield EJ (1981) Effect of insulin therapy on insulin resistance in type II diabetic subjects. Diabetes 30: 739-745

22. Hidaka H, Nagulesparan M, Klimes I, Clark R, Sasaki H, Aronoff SL, Vasques B, Rubenstein AH, Unger RH (1982) Improvement of insulin secretion but not insulin resistance after short term control of plasma glucose in obese type II diabetics. J Clin Endocrinol Metab 54: 217-222

23. Scarlett JA, Kolterman OG, Ciaraldi TP, Kao M, Olefsky JM (1983) Insulin treatment reverses the post-receptor defect in adipocyte 3-O-methylglucose transport in type II diabetes mellitus. J Clin Endocrinol Metab 56: 1195-1201

24. Garvey TW, Olefsky JM, Hamann RF, Kolterman OG (1985) The effect of insulin treatment on insulin secretion and insulin action in type II diabetes mellitus. Diabetes 34: 222-234

25. Randle PJ, Garland PB, Newsholme EA (1963) The glucose fatty acid cycle: its role in insulin sensitivity and the metabolic disturbances of diabetes mellitus. Lancet I: 785-789

26. Butterfield WJH, Whichelow MJ (1968) Effect of diet, sulpholnureas and phenformin on peripheral glucose uptake in diabetes and in obesity. Lancet I: 785-788

27. Lefebvre P, Luyckx A, Mosora F, Lacroix M, Pirnay F (1978) Oxidation of an exogenous glucose load using normally labelled C-13-glucose. Diabetologia 14: 39-45

28. Nattrass M, Alberti KGMM (1978) Biguanides. Diabetologia 14: 71-74

29. Corsini GU, Sirigu F, Tagliamonte P, Muntoni S (1974) Effects of biguanides on fatty acid and glucose oxidation in muscle. Pharmacol Res Commun 6: 253-261

30. Jangaard NO, Pereira JN, Pinson R (1968) Metabolic effects of the biguanides and possible mechanism of action. Diabetes 17 : 96-104

Received: 29 December 1988

and in revised form: 28 April 1989

Dr. L. Groop

Fourth Department of Medicine

Helsinki University Hospital

Unioninkatu 38

SF-00170 Helsinki

Finland 